\title{
Endometriosis and the neoplastic process
}

\author{
Rajesh Varma ${ }^{1,2}$, Terrance Rollason ${ }^{3}$, Janesh K Gupta ${ }^{2}$ and Eamonn R Maher ${ }^{1}$ \\ ${ }^{1}$ Section of Medical and Molecular Genetics, ${ }^{2}$ Academic Department of Obstetrics and Gynaecology and \\ ${ }^{3}$ Department of Histopathology, Birmingham Women's Hospital, Birmingham B15 2TG, UK
}

Correspondence should be addressed to R Varma; Email r.varma@bham.ac.uk

\begin{abstract}
Endometriosis is a frequent disorder that commonly presents with infertility and pelvic pain. Although the precise aetiology of endometriosis is unclear, it is generally considered to involve multiple genetic, environmental, immunological, angiogenic and endocrine processes. Genetic factors have been implicated in endometriosis but the susceptibility genes remain largely unknown. Although endometriosis is a benign disorder, recent studies of endometriosis suggest endometriosis could be viewed as a neoplastic process. Evidence to support this hypothesis includes the increased susceptibility to develop ovarian clear-cell and endometrioid cancers in the presence of endometriosis, and molecular similarities between endometriosis and cancer. In this article we discuss (i) the evidence suggesting that endometriosis might be viewed as a neoplastic process, and (ii) the implications of this hypothesis for elucidating the pathogenesis of endometriosis and developing novel methods of diagnostic classification and individualised treatments.

Reproduction (2004) 127 293-304
\end{abstract}

\section{What is endometriosis?}

Endometriosis is defined as the implantation of endometrium-like glandular and stromal cells outside their normal location in the uterus. Endometriotic lesions are usually identified at laparoscopy localised to ovaries and the pouch of Douglas (Fig. 1). Endometriosis is diagnosed in $30 \%$ of cases referred for infertility investigations (Lapp 2000 ) and in $10-70 \%$ of women with pelvic pain (Lapp 2000). Overall, studies estimate that endometriosis may affect around $7-15 \%$ of women of reproductive age, thus making this a common condition.

Endometriosis has been considered a 'disease' because it is often identified when investigating women with infertility, pelvic pain, dyspareunia (pain on intercourse) and dysmenorrhoea (painful periods). Traditionally the classification of endometriosis has been made by anatomical (surgical staging by revised American Fertility Society score) and histopathological (atypical and non-atypical endometriosis) criteria (Roberts \& Rock 2003). However, this combined approach of classification does not correlate closely with pelvic pain or reproductive outcome, and is prone to inter-observer error. Furthermore, the emphasis on targeting the endometriotic lesion, by surgical removal or hypo-oestrogenic inactivation, does not necessarily correct the aberrant underlying molecular mechanism(s). This explains why current endometriosis treatment does not alleviate clinical symptoms in all cases, and recurrence is common (Donnez et al. 2002).

These disparities suggest that endometriosis may not be a true 'disease' but a heterogeneous entity with differing subtypes. One subtype may be capable of causing symptomatic disease directly consequent to endometriotic pathology (e.g. ovarian endometriomas, pelvic adhesions). While another subtype may be associated with symptoms without an obvious endometriotic-lesion basis. Another subtype may be clinically asymptomatic and its presence be considered a normal 'non-pathogenic' phenomena. Consequently the current focus on treating the endometriotic lesion should be reconsidered, and efforts to understand the pathogenesis of endometriosis, and its temporospatial relationship with symptomology, should be increased.

\section{Endometriosis and the neoplastic process}

For some time, endometriosis research has focused on comparisons of various physiological processes in the endometrium (ectopic vs eutopic) of women affected by endometriosis, against unaffected women (Sharpe-Timms 2001). This has identified multiple anomalies in genetic, environment, angiogenic, endocrine, metabolic and immunological mechanisms. Some of these correlate with the severity of endometriosis and/or associated clinical 


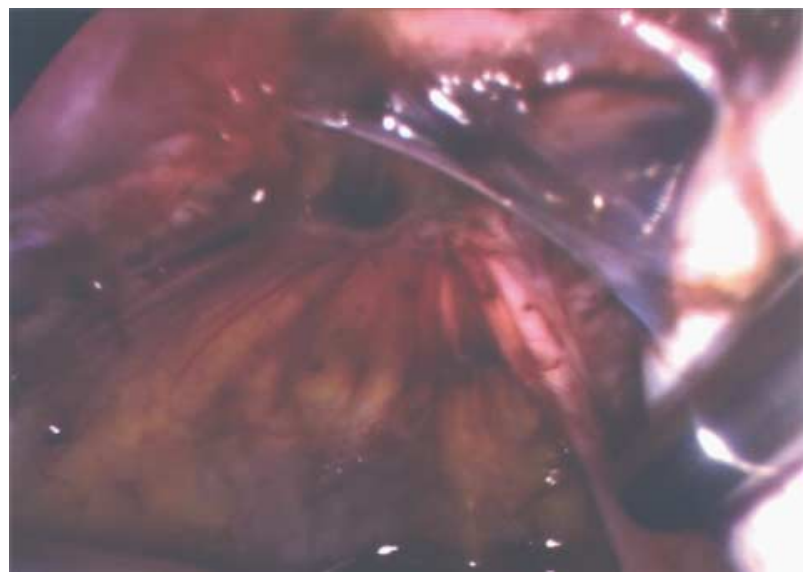

Figure 1 Typical uterosacral/pouch of Douglas endometriosis lesion.

sequelae implying a causative rather than simply associative role. However, the major obstacle has been the difficulty in discriminating between processes fundamental to endometriosis aetiopathogenesis and epiphenomena. Importantly, these physiological differences are multicompartmental (endometrium, peritoneal fluid, follicular fluid and blood) and not just localised to the site of the endometriotic lesion, implying a fundamental widespread alteration in reproductive tract function. This multifactorial multi-compartmental pathogenesis, coupled with the clinical heterogeneity, has created a confusion of data, with little consensus on a unifying mechanism.

Since Sampson first reported in 1925 (Sampson 1925) that endometriosis may give rise to malignant change, and proposed criteria for diagnosis of malignancy arising in endometriosis, extensive evidence for an association between endometriosis and cancer (especially ovarian) has accumulated. A recent landmark publication, 'Hallmarks of cancer' (Hanahan \& Weinberg 2000), defined seven critical features of the cancer phenotype (Table 1). To evaluate the hypothesis that endometriosis may be viewed as a neoplastic process, we review the (i) clinicopathological and (ii) molecular and genetic features of endometriosis in relation to the framework suggested by Hanahan. In addition, we outline how the hypothesis provides a basis for elucidating the pathogenesis of endometriosis and the prospect of using 'molecular signatures' for the classification and treatment of endometriosis.

\section{Clinicopathological similarities of endometriosis and cancer}

The histopathological and epidemiological evidence demonstrating the strong association between endometriosis and ovarian cancer is given in the following subsections. There are two hypotheses that could explain the link: (i) endometriotic implants may directly undergo malignant transformation, perhaps through an atypical endometriosis transition phase; and (ii) both endometriosis and cancer

Table 1 The hallmarks of cancer. The listed capabilities are mostly acquired directly, or indirectly, through changes in the genome of cancer cells.

Self-sufficiency in growth signals

Insensitivity to anti-proliferative signals

Resistance to apoptosis Limitless replicative potential

Sustained angiogenesis

Tissue invasion and metastasis

Genomic instability
Mitotic growth signals are needed for cells to move from a quiescent state into an active proliferative state. These signals are transmitted into the cell by transmembrane cell-surface receptors that bind to: diffusible growth factors, extracellular matrix (ECM) components, cell-to-cell adhesion interaction molecules

Growth inhibitory signals (soluble or immobilized in ECM and on surfaces of nearby cells) are received by transmembrane cell-surface receptors coupled to intracellular signalling circuits Evasion mechanisms of programmed cell death

Disruption of intrinsic cell-autonomous programme that limits their multiplication. This program operates independently of the cell-to-cell signalling pathways described above

Virtually all cells in a tissue are obligated to reside within $100 \mu \mathrm{m}$ of a capillary blood vessel to allow adequate permeation of oxygen and nutrients crucial for cell survival. The cells within aberrant proliferative lesions initially lack angiogenic ability, but in order to progress, incipient neoplasias must develop angiogenic ability

This enables cancer cells to escape the primary tumour mass and colonise new sites where, at least initially, nutrients and space are not limited

Mutations or inactivation/activation of TSGs, oncogenes, DNA monitoring and repair enzymes, checkpoint systems at mitosis. These are carried out by intragene (e.g. mutation, deletion) and epigenetic (e.g. promoter hypermethylation) mechanisms

share common antecedent mechanisms and/or predisposing factors (e.g. genetic susceptibility, immune/ angiogenic dysregulation, environmental toxin exposure), with obvious divergence in molecular pathways downstream.

\section{Histopathology}

Like malignancy, endometriosis displays features of atypia, adherence, invasion and metastases. Atypical endometriosis is characterised histologically by endometrial glands with cytological or architectural atypia (LaGrenade \& Silverberg 1988), and has been observed in $12-35 \%$ of ovarian endometriosis (Seidman 1996, Nishida et al. 2000, Bayramoglu \& Duzcan 2001). Around $60-80 \%$ of cases of endometriosis-associated ovarian cancer (EAOC) occur in the presence of atypical ovarian endometriosis (Fukunaga et al. 1997, Ogawa et al. 2000, Oral et al. 2003). Of these cases, $25 \%$ show direct continuity of the atypical ovarian endometriosis with ovarian cancer (Fukunaga et al. 1997), underlying a potential 'premalignant' transition spectrum of non-atypical to atypical and malignant variants. 


\section{Morphometry}

Morphometric analysis of cancer, used for assessing mitotic activity and grading, has been shown to correlate with clinical prognosis (Kronqvist et al. 2002). Although morphometric analysis of non-atypical endometriosis showed no difference between active (red) and inactive (black or white) lesions, it has yet to be studied in atypical endometriosis (Regidor et al. 2002). Nonetheless, mild cytological atypia in the glandular epithelium of endometriotic cysts has been associated with normal DNA diploid patterns, whereas severe atypia may be associated with aneuploidy (Ballouk et al. 1994).

\section{Ovarian malignancy may arise directly from ovarian endometriosis}

Around $60 \%$ of EAOCs occur with the cancer adjacent to endometriosis or arising directly from ovarian endometriosis, with the remaining $40 \%$ occurring with distant endometriotic disease (Erzen \& Kovacic 1998, Modesitt et al. 2002). Clear-cell and endometrioid carcinomas are the commonest EAOCs with ovarian endometriosis, while clear-cell adenocarcinoma and adenosarcoma are the commonest EAOCs in extra-ovarian endometriosis (Erzen \& Kovacic 1998, Stern et al. 2001, Zaino et al. 2001). The risk of direct malignant transformation of ovarian endometriosis has been estimated as $0.7-1.6 \%$ over an average of 8 years (Seidman 1996, Nishida et al. 2000). Interestingly, there is a common unexplained left-sided predominance for endometriotic cysts, and ovarian endometrioid and clear-cell cancers (Vercellini et al. 2000, Al Fozan \& Tulandi 2003).

\section{Increased risk of ovarian cancer in women with endometriosis, irrespective of whether endometriosis is distant or adjacent to ovarian tumour}

The age-standardised incidence of ovarian cancer in women in the UK is 21.9 per $100000(0.02 \%)$, with around $75 \%$ of cases diagnosed in postmenopausal women (National Statistics 2003). If there were no association between cancer and endometriosis then the incidence of endometriosis in women with ovarian cancer would be similar to that in the general population. However, the incidence of endometriosis in women with ovarian cancer is $8-30 \%$ (Fukunaga et al. 1997, Ogawa et al. 2000, Oral et al. 2003). This compares with a background incidence of endometriosis of $7-15 \%$ in women of reproductive age, and less than $2 \%$ in postmenopausal women (Lapp 2000). These data correlate with the finding from a Swedish population study, where the risk of ovarian cancer was increased 4.2 -fold (95\% confidence interval 2.07.7) in the presence of endometriosis (Brinton et al. 1997).

Furthermore, the histology of EAOC $(40-55 \%$ clearcell, $20-40 \%$ endometrioid and $<10 \%$ serous and mucinous subtypes) (Fukunaga et al. 1997, Yoshikawa et al. 2000, Modesitt et al. 2002) differs considerably from that seen in all ovarian cancers (FIGO 1998 annual report $55 \%$ serous, $13 \%$ mucinous, $14 \%$ endometrioid, $6 \%$ clear-cell) (Pecorelli et al. 1998).

\section{Increased risk of synchronous endometrial and ovarian cancers, especially endometrioid type, in the presence of endometriosis}

Simultaneously detected endometrial and ovarian carcinomas are most often associated with endometrioid subtypes, and ovarian endometriosis was identified in around $30 \%$ of these cases (Erzen \& Kovacic 1998, Stern et al. 2001, Zaino et al. 2001).

\section{Clinical behaviour and prognosis of EAOC differs from matched ovarian cancer subtypes not associated with endometriosis}

EAOC compared with ovarian cancer without endometriosis, presents at a less-advanced stage, lower grade, predominantly endometrioid and clear-cell type, and has a better overall survival (Erzen et al. 2001, Modesitt et al. 2002).

\section{Increased risk of extra-ovarian cancers}

Around $80 \%$ of intraperitoneal cancers associated with endometriosis relate to ovarian cancer, with the remainder extra-ovarian (Modesitt et al. 2002). A separate study showed an increased risk of extra-pelvic cancers (breast and non-Hodgkin's lymphoma) in women with endometriosis (Brinton et al. 1997).

\section{Molecular similarities of endometriosis and cancer}

In the following subsections we review the molecular and genetic features of endometriosis in relation to the characteristics of cancer suggested by Hanahan \& Weinberg (2000) (see Table 1).

\section{Self-sufficiency in growth signals}

Like uterine and breast cancer, endometriosis behaves as an oestrogen-dependent neoplasm. Endometriosis has specifically adapted to oestrogen-induced signalling by:

i) Increased local production of oestrogen through increased expression of aromatase cytochrome P450 expression but deficient $17 \beta$-hydroxysteroid dehydrogenase type 2 expression (which impairs inactivation of potent oestradiol to less-potent oestrone (Bulun et al. 2000b)).

ii) Increased responsiveness to oestrogen. There is increased oestrogen receptor $(E R-\alpha)$ expression in active (red lesions) compared with inactive (black lesions) endometriosis (Matsuzaki et al. 2001b).

iii) Inherited genetic polymorphisms in oestrogen and progesterone receptors (PRs), which predispose to 
endometriosis (Kitawaki et al. 2001, Wieser et al. 2002).

iv) Inherited genetic polymorphisms in drug-metabolising enzymes (CYP1A1, CYP19 and GSTM1) which predispose to endometriosis (Baranova et al. 1999, Hadfield et al. 2001, Nakago et al. 2001, Arvanitis et al. 2003) and ovarian endometrioid and clear-cell cancers (Baxter et al. 2001). These alterations may induce endometriosis or cancer by altering a dioxininduced oestrogen growth signal. Dioxins are environmental contaminants, and have been shown to induce endometriosis-like and oestrogen-dependent tumours in animal models (Birnbaum \& Cummings 2002). Of importance, there is a doubled risk of developing endometriosis amongst women with high serum dioxin levels (Eskenazi et al. 2002). Activation of ERs in endometriosis may occur indirectly through up-regulated CYP1A1 activity, which causes increased aromatase P450 and oestrogen production (Bulun et al. 2000a), or directly by dioxin-activated aryl hydrocarbon receptor (Ohtake et al. 2003).

Other growth factors, such as transforming growth factor- $\alpha$ and insulin-like growth factor-I (IGF-I) have also been implicated in endometriosis and cancer development (Lebovic et al. 2001). IGF-I signalling is required for cell-cycle progression and appears to be a pre-requisite for malignant transformation and implantation. A higher risk for cervical, ovarian and endometrial cancer is related to high IGF-I levels in post- and premenopausal women. Plasma IGF-I levels are higher in cases of severe endometriosis; however, in endometriosis IGF-I levels locally in the endometrium are reduced (Druckmann \& Rohr 2002).

\section{Insensitivity to anti-proliferative signals}

Cell division relies on the activation of cyclins (e.g. cyclin D1), which bind to cyclin-dependent kinases (cdk) to induce cell-cycle progression towards S phase and later to initiate mitosis. Since uncontrolled cdk activity is often the cause of human cancer, their function is tightly regulated by cdk inhibitors (e.g. p21 and p27 Cip/Kip proteins). For example, increased expression of cyclin D1 and cdk occurs in breast cancer and is associated with poor outcome.

At the cellular level, differences in expression of p27Kip1 protein (cdk inhibitor) in active and inactive endometriotic lesions (Matsuzaki et al. 2001a), coupled with increased p21 expression in endometriomas compared with benign and malignant ovarian tumours (Fauvet et al. 2003), suggest a role for increased cdk activity through reduced cell-cycle inhibitor activity, which is an imbalance frequently seen in cancer.

At the tissue level, endometriosis may resist the antiproliferative effect of progesterone by the predominant expression of the inhibitory PR-A isoform instead of the stimulatory PR-B isoform (Attia et al. 2000).

\section{Resistance to apoptosis}

Malignancy commonly displays overexpression of antiapoptotic (BCl-2), under-expression of pro-apoptotic (BAX) factors, and inactivation of p53 gene (p53 is a tumour suppressor gene (TSG) whose protein (TP53) is pro-apoptotic) through mutation. Similarly, endometriotic lesions have also evolved strategies to evade apoptosis by: (i) increased $\mathrm{BCl}-2$, and decreased BAX (Meresman et al. 2000); (ii) upregulation of survivin and matrix metalloproteinases (MMPs) (Ria et al. 2002, Ueda et al. 2002a); (iii) elevated soluble Fas ligand (FasL) and interleukin (IL)-8 in endometriotic peritoneal fluid (the increased FasL expression by IL-8 may induce apoptosis of T lymphocytes and thus enable endometriosis to evade immune-mediated cell death (Garcia-Velasco et al. 2002)); and (iv) germline (Chang et al. 2002) and somatically acquired (Bischoff et al. 2002) inactivating mutations of p53 gene.

\section{Limitless replicative potential}

With each replicative cycle, telomeres (repetitive DNA sequences capping each chromosome) become progressively shorter, eventually resulting in cell senescence and cell death. Tumours commonly express the enzyme telomerase, which protects the telomeres from shortening and thus preventing 'cell ageing'. Oestrogen and progesterone stimulate, while tamoxifen and wild-type (normal variant) p53 inhibit, telomerase activity in breast and endometrial cancer cells (Vidal et al. 2002, Wang et al. 2002). Although there are no published studies examining telomerase function in endometriosis, it is notable that estrogen-dependent neoplasms are potentially susceptible to telomerase control.

\section{Sustained angiogenesis}

Pathological angiogenesis, immune cell suppression and immune cell activation co-exist in endometriosis and cancer processes (Folkman 2002, Gazvani \& Templeton 2002). Genetically transmitted or environmentally induced (e.g. exposure to dioxins) alterations in the angiogenic and/or immune response may predispose women to the ectopic implantation of endometrial cells, transported into the peritoneal cavity by retrograde menstruation, which thereby leads to endometriosis. Significantly, both cancer and endometriosis share some of the mediators implicated in this 'inflammatory angiogenesis' model. Furthermore, the genes of these mediators exhibit genetic polymorphisms that predispose either to endometriosis (e.g. intercellular adhesion molecule-1, IL-6 and IL-10 gene promoters) (Kitawaki et al. 2002, Vigano et al. 2003, Wieser et al. 2003) or to cancer (e.g. IL-6, IL-8, tumour necrosis factor (TNF)- $\alpha$, NFKB-1, and peroxisome proliferator-activated receptor- $\gamma$ genes) (Landi et al. 2003).

Anti-angiogenic therapy involves the inhibition of proangiogenic factors (e.g. anti-vascular endothelial growth factor (VEGF) monoclonal antibodies) or activation of 
endogenous inhibitors of angiogenesis (e.g. endostatin and angiostatin). Pre-clinical studies have shown that endostatin effectively inhibits tumour growth and shrinks existing tumour blood vessels. Phase 1 clinical cancer trials of endostatin and angiostatin are ongoing, and preliminary results show minimal toxicities. Similarly, anti-angiogenic strategies for treating endometriosis exist, but are still at the experimental phase (Hull et al. 2003). Soluble truncated receptor (Flt-1) and an affinity-purified antibody to human VEGF-A, significantly inhibited the growth of endometrial explants in a mouse in vivo model of endometriosis by disrupting the vascular supply. Gene transfection (using a replication-deficient adenovirus vector AdAngiostatin) of the endogenous angiogenesis inhibitor angiostatin to the peritoneum of a mouse was successful in treating a mouse in vivo model of endometriosis (Dabrosin et al. 2002).

\section{Tissue invasion and metastasis}

The ability to invade through the basement membranes characterises the transition from non-invasive to invasive cancer. Tumours secret proteases (e.g. MMPs) to degrade the basement membrane and surrounding stroma. Expression of MMP-2 and MMP-9 is correlated with grade and stage of many cancers. Likewise, MMP activity is up-regulated in endometriotic lesions (Mizumoto et al. 2002).

De-regulation of cell adherence signalling involving integrins, $\beta$-catenin, E-cadherin and P-cadherin has been demonstrated in the genesis of a number of malignancies (Morin 1999), and has also been implicated in endometriosis aetiopathogenesis (Scotti et al. 2000, Witz et al. 2000, GT Chen et al. 2002, Ueda et al. 2002b). $\beta$-Catenin mutations have been identified in endometrial and ovarian endometrioid cancers (Palacios \& Gamallo 1998, MorenoBueno et al. 2001) but have not been looked for in endometriosis. Cytokeratin-positive and E-cadherin-negative endometriotic cells have an invasive phenotype in an in vitro collagen invasion assay similar to metastatic carcinoma cells (Starzinski-Powitz et al. 1999).

\section{Genomic instability}

The classic model of malignant transformation of the cell involves the stepwise acquisition of multiple genetic alterations, which confers a clonal selective advantage at each step, predisposing to the next step (Lengauer et al. 1998). This is often accompanied by activation of protooncogenes to oncogenes (transformation of normal cellular growth, proliferation and differentiation genes) and inactivation of TSGs (genes that encode for proteins which inhibit excess cellular proliferation and malignant transformation). The genetic alterations can occur at different levels and include single nucleotides, small stretches of DNA (microsatellites), whole genes, chromosomal components or whole chromosomes. The genetic alterations can be intragene or epigenetic (e.g. gene silencing by promoter hypermethylation). Six principal genetic mechanisms have been identified to contribute to genomic instability in cancer, but only the first three have been looked for in endometriosis:

i) Gain in oncogenic activity

ii) Inactivation of TSG (loss of both gene copies of allele confers functional loss), or inactivation of haploinsufficient TSG (loss of only a single gene copy of allele confers functional loss)

iii) Anomalies in DNA mismatch repair enzymes, identified by microsatellite instability (MSI)

iv) Inactivation of genes that monitor genomic instability at cell cycling (e.g. mitotic spindle assembly checkpoint genes)

v) Telomere dysfunction (provokes chromosomal aberrations initiating carcinogenesis) and telomerasemediated telomere maintenance (enables cells to achieve a fully malignant endpoint and metastasis)

vi) Hypermethylation

These mechanisms often act in synergy to promote genomic instability and tumour cell proliferation. For example, deficiency of the TSG p53 alters the cellular response to DNA damage, in that it leaves cells with attenuated DNA damage checkpoint controls and a reduced propensity for apoptotic cell death. Thus, although the DNA repair capacity of these cells is reduced, survival is increased. This promotes genomic instability and contributes to the resistance of p53-deficient cells to cytotoxic agents.

Importantly, pre-malignant lesions display similar genetic aberrations to established cancer. Loss of mismatch repair enzyme activity, and loss of PTEN (phosphatase and tensin homologue gene) and p53 TSGs frequently occurs in premalignant and malignant stages of breast, endometrial and ovarian carcinomas (Obata et al. 1998, Codegoni et al. 1999, Saito et al. 2000, Lalloo \& Evans 2001, Mills et al. 2001). Furthermore, epithelial-stromal interactions are important in the tumour microenvironment and tumour development. Mutually exclusive germline mutations in PTEN and TP53 have been reported in epithelial and stromal cells of breast cancer underlying the co-dependence of these two cell types in tumourigenesis (Kurose et al. 2002).

In a similar manner, endometriosis demonstrates somatically acquired genetic alterations analogous to those found in cancer, resulting in the clonal expansion of genetically abnormal cells. The genetic evidence supporting the 'pre-neoplastic' state of endometriosis involves the following:

\section{Monoclonality}

Most neoplasms are monoclonal in origin and evidence for monoclonality of endometriosis has been demonstrated in several studies (Jimbo et al. 1997, Tamura et al. 1998, 
Wu et al. 2003), although these findings have been challenged recently (Mayr et al. 2003).

\section{Comparative genomic hybridisation $(\mathrm{CGH})$}

CGH has shown over-representation (increased copy-number) of chromosomes 1, 2, 3, 5, 6p, 7, 16, 17q, 20, 21q and $22 q$ in an endometriosis cell culture line FbEM-1, while chromosomes 5p, 6q, 9q, 11p, 12, 13q, 18 and X were under-represented. $\mathrm{CGH}$ repeated in endometriotic tissue revealed loss of DNA copy number on $1 p, 22 q$ and chromosome $X$, while gain on $6 p$ and $17 q$. Fluorescent in situ hybridisation (FISH) analysis confirmed that the gain at $17 q$ includes amplification of the proto-oncogene HER-2/neu (Gogusev et al. 1999, 2000).

\section{FISH}

FISH analysis of late-stage endometriotic lesions showed monosomy of chromosome 17, and loss of TP53 (17p13.1) locus. Because not all endometriotic cells displayed this genetic alteration it was suggested that this was a somatically acquired mutation, perhaps occurring in mainly advanced endometriosis states (Kosugi et al. 1999, Bischoff et al. 2002).

\section{Loss of heterozygosity ( $\mathrm{LOH}$ )}

$\mathrm{LOH}$ commonly indicates regions of TSG inactivation, and has been identified in endometriosis and endometriosis-derived cell lines at 5q, 6q, 9p, 10q, 11q, 22q, p16 (Ink4), galactose-1-phosphate uridy Itransferase, p53 and apolipoprotein All (Jiang et al. 1996, Obata \& Hoshiai 2000, Thomas \& Campbell 2000, Goumenou et al. 2001). Importantly, cases with ovarian cancer adjacent to endometriosis or arising from endometriosis showed common genetic $\mathrm{LOH}$ alterations in the endometriosis and cancer, indicating a possible malignant genetic transition spectrum between endometriosis and cancer (Jiang et al. 1998, Campbell \& Thomas 2001).

\section{MSI}

Hypermethylation of hMLH1 (whose gene product is a component of the DNA mismatch repair pathway), with concurrent absence of $\mathrm{hMLH} 1$ protein expression, is noted in $8.6 \%$ of endometriotic lesions (Martini et al. 2002).

\section{Somatic mutations in TSGs}

Mutations of PTEN, a TSG, were identified in 20\% of ovarian endometrioid carcinomas (EAOC and sporadic) and $20 \%$ of solitary endometrial cysts, suggesting that inactivation of the PTEN is an early event in the malignant transformation of endometriotic implants (Sato et al. 2000). A separate study identified reduced PTEN protein expression in $15 \%$ of endometriosis cases (Martini et al. 2002).

\section{Germline mutations in TSGs}

As stated earlier, there are germline (Chang et al. 2002) and somatically acquired (Bischoff et al. 2002) inactivating mutations of the p53 gene.

\section{Evidence from EAOCs arising from endometriosis}

Endometrioid EAOCs arising from endometriosis show higher expression of p53 and c-erB-2 oncoproteins than similar ovarian endometrioid cancers without endometriosis (Prefumo et al. 2003). The different pattern of expression in the two groups suggests different molecular pathways and could explain variations in cancer subtype and prognosis between the two groups (Erzen et al. 2001, Modesitt et al. 2002).

\section{Implications of the 'endometriosis is a neoplastic process' hypothesis}

In summary, there is extensive clinicopathological, molecular and genetic evidence supporting the hypothesis that endometriosis is a neoplastic process with a potential for malignant transformation. Like sporadic cancer (Balmain et al. 2003), endometriosis may be considered to arise by complex interactions between inherited germline polygenic low-penetrance alleles (polymorphisms) (Hadfield et al. 2001, Zondervan et al. 2001), somatically acquired genetic alterations (Campbell \& Thomas 2001), environmental factors (Birnbaum \& Cummings 2002), and the processes of the hallmarks of cancer described earlier. A visual summary of the main pathways of this hypothesis is shown in Fig. 2. Acceptance of this hypothesis permits the use of investigative strategies that have proved successful in defining the molecular processes that underlie cancer: genomic, transcriptomic and proteomic profiling. Thus the analysis of genetic changes associated with normal endometrium, non-atypical, atypical and EAOC lesions could define the sequential changes involved in the initiation, proliferation and malignant transformation of endometriosis.

\section{Genomic profiling of endometriosis}

$\mathrm{CGH}$ studies have been undertaken in endometriosis, but could only detect relatively large-scale deletions or duplications. Improved sensitivity and throughput could be achieved by the use of high-throughput matrix array-based $\mathrm{CGH}$ (Veltman et al. 2003). Rapid detailed LOH analysis could also be achieved using single nucleotide polymorphism (SNP) microarray-based chips (Hoque et al. 2003, Marnellos 2003).

\section{Transcriptomic profiling of endometriosis}

Gene expression microarray analysis has been demonstrated to provide better subclassification and prognostic predictions than conventional histopathology in many 
CLONALITY

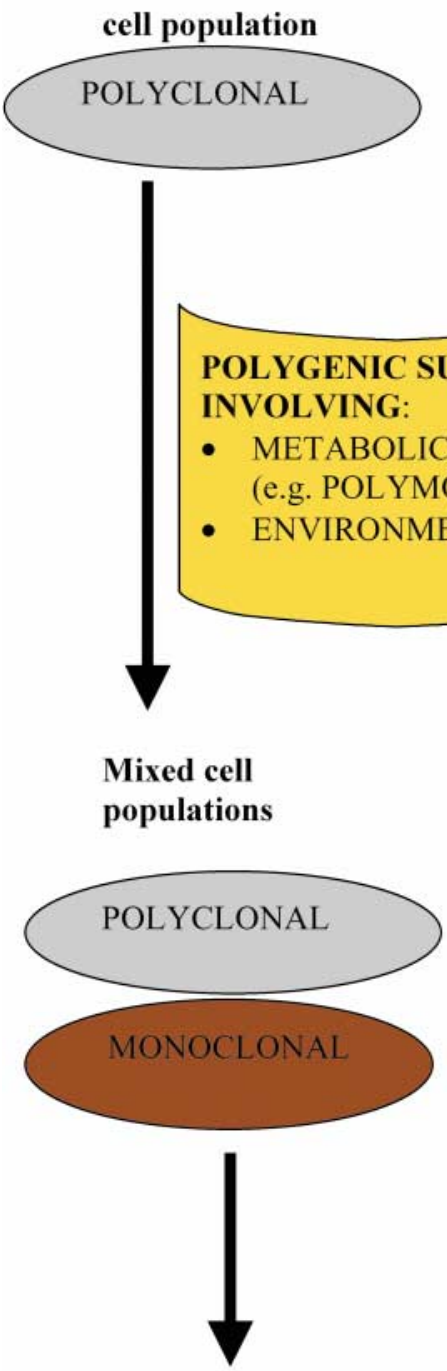

Predominant cell population

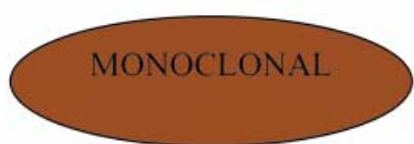

Entire cell population

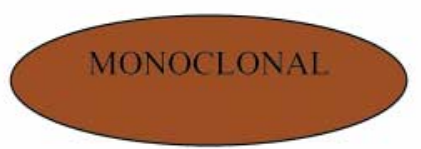

GENETIC

CANCER HALLMARK MECHANISMS

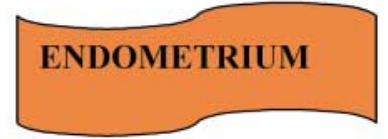

RETROGRADE MENSTRUATION

(? also Coelomic metaplasia, lymphovascular spread)

ADHESION (cadherin,

$B$-catenin, protein kinase $C$

PROLIFERATION (limited)

ANGIOGENESIS (limited)

EVASION OF APOPTOSIS

STEPWISE ACQUISITION OF GENETIC ALTERATIONS

(e.g. TSG, oncogenes)

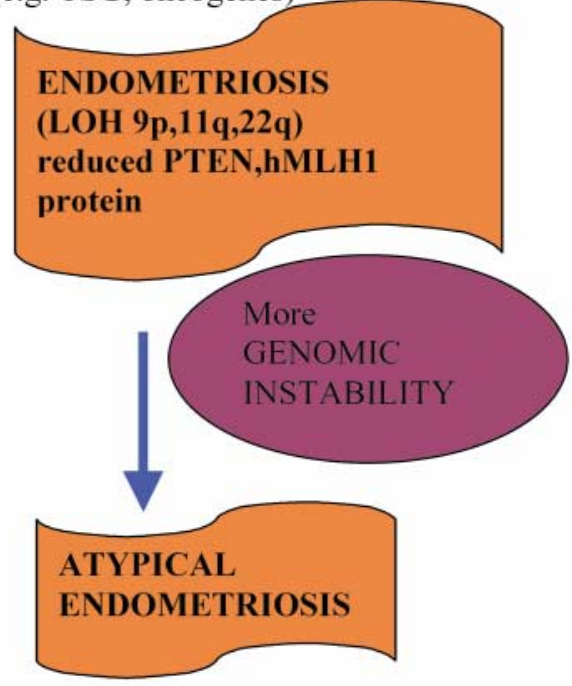

PRE-MALIGNANT

TRANSITION PHASE/ZONE

(? further LOH 6q,5q,9p,11q,22q,

PTEN, TP53, beta-catenin, P-cadherin)

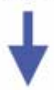

OVARIAN ENDOMETRIOID AND CLEAR CELL CARCINOMA
SELF-SUFFICIENCY IN GROWTH SIGNALS

(cylcin, cdk, p14, p16)

INSENSITIVITY TO GROWTH INHIBITION

APOPTOSIS EVASION

(Fas, Bax, p21, p53, p14)

LIMITLESS

REPLICATION

PATHOLOGICAL ANGIOGENESIS

PROLIFERATION OF CHROMOSOMALLY ABNORMAL CELLS

INVASION \& METASTASIS

Figure 2 Proposed model for endometriosis pathogenesis based on cancer framework. 
cancers (van de Vijver et al. 2002, Liu 2003). Notably, DNA microarrays have been recently undertaken in endometriosis (Eyster et al. 2002, Kao et al. 2003), endometrial cancer (Mutter et al. 2001, Risinger et al. 2003), normal endometrium (Borthwick et al. 2003), and endometrium of women with endometriosis (H-W Chen et al. 2002). Indeed, the combination of $\mathrm{CGH}$ and expression microarrays (Bayani et al. 2002, Tay et al. 2003), or SNP microarrays could be valuable for prioritising the analysis of candidate TSGs and proto-oncogenes (Dobrin \& Stephan 2003).

\section{Proteomic profiling of endometriosis}

This is a complementary approach to genomic profiling. Immunohistochemistry can be used to provide a limited proteomic profile, but recently developed high throughput proteomic technology (e.g. mass spectrometry, matrixassisted laser desorption and ionisation time-of-flight, surface enhanced laser desorption and time-of-flight, and protein microarrays) promise the capacity to define a wide-ranging proteomic profile (Dobrin \& Stephan 2003).

\section{Molecular re-classification of endometriosis}

Genomic and proteomic profiling should provide new insights into the pathogenesis of endometriosis and malignant transformation. A better understanding of reproductive tract molecular pathology, and the temporo-spatial relationship of endometriosis with clinical sequelae, allows the development of novel therapies targeted to the aberrant process at the molecular level, rather than focussing solely on endometriotic lesion eradication. Examples of agents under investigation for endometriosis and cancer using the cancer hallmark model are listed in Table 2. However, it should be noted there is considerable overlap in the endocrine, metabolic, angiogenic, immunological roles of the mediators implicated in endometriosis and cancer. Thus great care should be taken in delivering

Table 2 Individual therapeutic approaches to endometriosis according to cancer cell hallmarks. Consequent to endometriosis heterogeneity, the exact contribution of each hallmark component may vary between individuals and clinical symptoms. Nevertheless, therapies can be designed to target predominant categories following endometriosis molecular classification (expression signature).

\begin{tabular}{|c|c|c|}
\hline Cancer cell hallmark & $\begin{array}{l}\text { Targets under evaluation in endometriosis } \\
\text { based on agents used in cancer trials }\end{array}$ & Targets/ putative targets under investigation in cancer \\
\hline $\begin{array}{l}\text { Self-sufficiency } \\
\text { in growth signals }\end{array}$ & $\begin{array}{l}\text { Aromatase inhibitors, selective ER (e.g. } \\
\text { Arzoxifene) and PR modulators, Mirena coil, } \\
\text { gonadotrophin-releasing hormone antagonists } \\
\text { (e.g. cetrorelix) }\end{array}$ & $\begin{array}{l}\text { Inhibitors of: mitogen-activated protein kinase inhibitors, HER-2 } \\
\text { receptor (trastuzumab), IGF-I receptor, EGFR (erbitux), } \\
\text { EGFR tyrosine kinase (gefitinib), farneysl transferase, } \\
\text { Bcr-Abl tyrosine kinase (imatinib mesylate) }\end{array}$ \\
\hline $\begin{array}{l}\text { Insensitivity to } \\
\text { anti-proliferative signals }\end{array}$ & - & $\begin{array}{l}\text { Proteasome inhibitors (bortezomib), cdk inhibitors } \\
\text { (flavopiridol) }\end{array}$ \\
\hline Resistance to apoptosis & $\begin{array}{l}\text { Angiostatin gene transfer, transfection with } \\
\text { pro-apoptotic (e.g. BAX) gene; COX-2 inhibitors }\end{array}$ & $\begin{array}{l}\text { COX-2 inhibitor (celecoxib), thalidomide, apoptosis } \\
\text { inducers (exisulind inhibits cGMP). } \\
\text { Immunotherapy by genetically modified tumour } \\
\text { vaccines (e.g. HER-2 peptide vaccination) or } \\
\text { humoral factors (e.g. immunokines like } \\
\text { IL-12, TNF antagonists; monoclonal antibody } \\
\text { to CA-125 (ovarex), recombinant immunotoxin } \\
\text { to mesothelin) }\end{array}$ \\
\hline $\begin{array}{l}\text { Limitless replicative } \\
\text { potential }\end{array}$ & - & Telomerase modifiers \\
\hline Sustained angiogenesis & $\begin{array}{l}\text { Anti-VEGF monoclonal antibody (bevacizumab), } \\
\text { VEGF receptor tyrosine kinase inhibitors }\end{array}$ & $\begin{array}{l}\text { Angiozyme (cleaves mRNA for Flt-1, } \\
\text { the main receptor for VEGF), } \\
\text { protein kinase C-beta inhibitor (LY317615), } \\
\text { COX-2 inhibitor, thalidomide, lysophosphatidic acid } \\
\text { inhibitors }\end{array}$ \\
\hline $\begin{array}{l}\text { Tissue invasion and } \\
\text { metastasis }\end{array}$ & - & $\begin{array}{l}\text { Inhibit/modify catenin/cadherin signalling, selective MMP } \\
\text { inhibitors }\end{array}$ \\
\hline Genomic instability & - & $\begin{array}{l}\text { Gene therapy to deliver therapeutic or corrective gene to alter } \\
\text { oncogenes/TSG balance. Genes may be } \\
\text { delivered by infectious (adenovirus) or } \\
\text { non-infectious (liposome) vectors. Examples: } \\
\text { - Adenoviral E1A (oppose HE-2/neu oncogene), } \\
\text { - Adenovirus transfection of wild-type p53 } \\
\text { (restore TSG) } \\
\text { - Transfect viral suicide genes like } \\
\text { HSV thymidine kinase (sensitises to } \\
\text { ganciclovir cytotoxicity) } \\
\text { - Antisense oligonucletoides (targeting proto-oncogenes, } \\
\text { - Tribogenes like c-myc, protein kinase C-alpha (affinitak) }\end{array}$ \\
\hline
\end{tabular}

EGFR, epidermal growth factor receptor; COX-2, cyclooxygenase-2. 
the agent and selecting the mechanism to be targeted, in order to avoid systemic compromise, or impairing other critical aspects of reproductive tract function (e.g. fertility).

Genomic and proteomic profiling may resolve the heterogeneity of endometriosis into around 10-20 distinct endometriotic 'signatures'. Each molecular 'signature' may correlate more closely to: location (ovarian, pouch of Douglas), invasiveness, atypical compared with nonatypical histology, infertility compared with pelvic pain, susceptibility to malignant transformation, sensitivity or resistance to various therapies. Thus clinical endometriosis treatments could be individualised to the specific expression 'signature'. Furthermore, testing for specific 'signatures' in accessible cells (e.g. serum, endometrial and endometriotic biopsies) could form the basis of a sensitive population-wide screening method. Although, in the case of predicting endometriosis malignant transformation susceptibility, research would be needed to assess how these relatively expensive and labour-intensive tests compare against simpler and cheaper immunohistochemistry and/or computerised nuclear morphometry.

\section{Conclusion}

Endometriosis possesses many features of a benign neoplastic process with the potential for malignant transformation. Application of strategies used in the investigation of cancer should provide new insights into the classification and molecular pathogenesis and of endometriosis.

\section{Acknowledgements}

This work, and R V, are supported by grants from the Royal College of Obstetricians and Gynaecologists Endometriosis Millennium Fund 2003, and a Springboard Fellowship funded jointly by Birmingham Women's Hospital and the University of Birmingham.

\section{References}

Al Fozan H \& Tulandi T 2003 Left lateral predisposition of endometriosis and endometrioma. Obstetrics and Gynecology 101 164-166.

Arvanitis DA, Koumantakis GE, Goumenou AG, Matalliotakis IM, Koumantakis EE \& Spandidos DA 2003 CYP1A1, CYP19, and GSTM1 polymorphisms increase the risk of endometriosis. Fertility and Sterility 79 (Suppl 1) 702-709.

Attia GR, Zeitoun K, Edwards D, Johns A, Carr BR \& Bulun SE 2000 Progesterone receptor isoform $A$ but not $B$ is expressed in endometriosis. Journal of Clinical Endocrinology and Metabolism 85 2897-2902.

Ballouk F, Ross JS \& Wolf BC 1994 Ovarian endometriotic cysts. An analysis of cytologic atypia and DNA ploidy patterns. American Journal of Clinical Pathology 102 415-419.

Balmain A, Gray J \& Ponder B 2003 The genetics and genomics of cancer. Nature Genetics 33 (Suppl) 238-244.

Baranova H, Canis M, Ivaschenko T, Albuisson E, Bothorishvilli R, Baranov V, Malet P \& Bruhat MA 1999 Possible involvement of arylamine $\mathrm{N}$-acetyltransferase 2, glutathione S-transferases M1 and
T1 genes in the development of endometriosis. Molecular Human Reproduction 5 636-641.

Baxter SW, Thomas EJ \& Campbell IG 2001 GSTM1 null polymorphism and susceptibility to endometriosis and ovarian cancer. Carcinogenesis 22 63-65.

Bayani J, Brenton JD, Macgregor PF, Beheshti B, Albert $M$, Nallainathan D, Karaskova J, Rosen B, Murphy J, Laframboise S, Zanke B \& Squire JA 2002 Parallel analysis of sporadic primary ovarian carcinomas by spectral karyotyping, comparative genomic hybridization, and expression microarrays. Cancer Research 62 $3466-3476$

Bayramoglu H \& Duzcan E 2001 Atypical epithelial changes and mutant p53 gene expression in ovarian endometriosis. Pathology Oncology Research $733-38$.

Birnbaum LS \& Cummings AM 2002 Dioxins and endometriosis: a plausible hypothesis. Environmental Health Perspectives $\mathbf{1 1 0}$ $15-21$.

Bischoff FZ, Heard M \& Simpson JL 2002 Somatic DNA alterations in endometriosis: high frequency of chromosome 17 and p53 loss in late-stage endometriosis. Journal of Reproductive Immunology 55 49-64.

Borthwick JM, Charnock-Jones DS, Tom BD, Hull ML, Teirney R, Phillips SC \& Smith SK 2003 Determination of the transcript profile of human endometrium. Molecular Human Reproduction 9 $19-33$.

Brinton LA, Gridley G, Persson I, Baron J \& Bergqvist A 1997 Cancer risk after a hospital discharge diagnosis of endometriosis [Comment]. American Journal of Obstetrics and Gynecology $\mathbf{1 7 6}$ $572-579$.

Bulun SE, Zeitoun KM \& Kilic G 2000a Expression of dioxin-related transactivating factors and target genes in human eutopic endometrial and endometriotic tissues. American Journal of Obstetrics and Gynecology 182 767-775.

Bulun SE, Zeitoun KM, Takayama K \& Sasano H $2000 b$ Estrogen biosynthesis in endometriosis: molecular basis and clinical relevance. Journal of Molecular Endocrinology 25 35-42.

Campbell IG \& Thomas EJ 2001 Endometriosis: candidate genes. Human Reproduction Update 7 15-20.

Chang CC, Hsieh YY, Tsai FJ, Tsai CH, Tsai HD \& Lin CC 2002 The proline form of p53 codon 72 polymorphism is associated with endometriosis. Fertility and Sterility 77 43-45.

Chen GT, Tai CT, Yeh LS, Yang TC \& Tsai HD 2002 Identification of the cadherin subtypes present in the human peritoneum and endometriotic lesions: potential role for P-cadherin in the development of endometriosis. Molecular Reproduction and Development $\mathbf{6 2}$ 289-294.

Chen H-W, Li H-N, Lee Y-T, Yang P-C, Chen JJW \& Tzeng C-R 2002 Global analysis of differentially expressed genes in endometrium with or without endometriosis using human cDNA microarray. Fertility and Sterility 77 S16.

Codegoni AM, Bertoni F, Colella G, Caspani G, Grassi L, D'Incalci M \& Broggini M 1999 Microsatellite instability and frameshift mutations in genes involved in cell cycle progression or apoptosis in ovarian cancer. Oncology Research 11 297-301.

Dabrosin C, Gyorffy S, Margetts P, Ross C \& Gauldie J 2002 Therapeutic effect of angiostatin gene transfer in a murine model of endometriosis. American Journal of Pathology 161 909-918.

Dobrin SE \& Stephan DA 2003 Integrating microarrays into diseasegene identification strategies. Expert Review of Molecular Diagnostics 3 375-385.

Donnez J, Squifflet J, Pirard C, Jadoul P, Wyns C \& Smets M 2002 The efficacy of medical and surgical treatment of endometriosisassociated infertility and pelvic pain. Gynecologic and Obstetric Investigation 54 (Suppl 1) 2-7.

Druckmann R \& Rohr UD 2002 IGF-I in gynaecology and obstetrics: update 2002. Maturitas 41 (Suppl 1) S65-S83.

Erzen M \& Kovacic J 1998 Relationship between endometriosis and ovarian cancer. European Journal of Gynaecological Oncology 19 $553-555$. 
Erzen M, Rakar S, Klancar B \& Syrjanen K 2001 Endometriosisassociated ovarian carcinoma (EAOC): an entity distinct from other ovarian carcinomas as suggested by a nested case-control study. Gynecologic Oncology 83 100-108.

Eskenazi B, Mocarelli P, Warner M, Samuels S, Vercellini P, Olive D, Needham LL, Patterson DG Jr, Brambilla P, Gavoni N, Casalini S, Panazza S, Turner W \& Gerthoux PM 2002 Serum dioxin concentrations and endometriosis: a cohort study in Seveso, Italy. Environmental Health Perspectives 110 629-634.

Eyster KM, Boles AL, Brannian JD \& Hansen KA 2002 DNA microarray analysis of gene expression markers of endometriosis. Fertility and Sterility 77 38-42.

Fauvet R, Poncelet C, Hugol D, Lavaur A, Feldmann G \& Darai E 2003 Expression of apoptosis-related proteins in endometriomas and benign and malignant ovarian tumours. Virchows Archiv 443 $38-43$.

Folkman J 2002 Role of angiogenesis in tumor growth and metastasis. Seminars in Oncology 29 (Suppl 16) 15-18.

Fukunaga M, Nomura K, Ishikawa E \& Ushigome S 1997 Ovarian atypical endometriosis: its close association with malignant epithelial tumours. Histopathology 30 249-255.

Garcia-Velasco JA, Mulayim N, Kayisli UA \& Arici A 2002 Elevated soluble Fas ligand levels may suggest a role for apoptosis in women with endometriosis. Fertility and Sterility 78 855-859.

Gazvani R \& Templeton A 2002 Peritoneal environment, cytokines and angiogenesis in the pathophysiology of endometriosis. Reproduction 123 217-226.

Gogusev J, Bouquet DJ, Telvi L, Doussau M, du Manoir S, Stojkoski A \& Levardon M 1999 Detection of DNA copy number changes in human endometriosis by comparative genomic hybridization. Human Genetics 105 444-451.

Gogusev J, Bouquet DJ, Telvi L, Doussau M, du Manoir S, Stojkoski A \& Levardon M 2000 Genetic abnormalities detected by comparative genomic hybridization in a human endometriosis-derived cell line. Molecular Human Reproduction 6 821-827.

Goumenou AG, Arvanitis DA, Matalliotakis IM, Koumantakis EE \& Spandidos DA 2001 Microsatellite DNA assays reveal an allelic imbalance in p16(Ink4), GALT, p53, and APOA2 loci in patients with endometriosis. Fertility and Sterility 75 160-165.

Hadfield RM, Manek S, Weeks DE, Mardon HJ, Barlow DH \& Kennedy SH 2001 Linkage and association studies of the relationship between endometriosis and genes encoding the detoxification enzymes GSTM1, GSTT1 and CYP1A1. Molecular Human Reproduction 7 1073-1078.

Hanahan D \& Weinberg RA 2000 The hallmarks of cancer. Cell 100 $57-70$.

Hoque MO, Lee CC, Cairns P, Schoenberg M \& Sidransky D 2003 Genome-wide genetic characterization of bladder cancer: a comparison of high-density single-nucleotide polymorphism arrays and PCR-based microsatellite analysis. Cancer Research 63 $2216-2222$.

Hull ML, Charnock-Jones DS, Chan CL, Bruner-Tran KL, Osteen KG, Tom BD, Fan TP \& Smith SK 2003 Antiangiogenic agents are effective inhibitors of endometriosis. Journal of Clinical Endocrinology and Metabolism 88 2889-2899.

Jiang X, Hitchcock A, Bryan EJ, Watson RH, Englefield P, Thomas EJ \& Campbell IG 1996 Microsatellite analysis of endometriosis reveals loss of heterozygosity at candidate ovarian tumor suppressor gene loci. Cancer Research 56 3534-3539.

Jiang X, Morland SJ, Hitchcock A, Thomas EJ \& Campbell IG 1998 Allelotyping of endometriosis with adjacent ovarian carcinoma reveals evidence of a common lineage. Cancer Research $\mathbf{5 8}$ 1707-1712.

Jimbo H, Hitomi Y, Yoshikawa H, Yano T, Momoeda M, Sakamoto A, Tsutsumi O, Taketani Y \& Esumi H 1997 Evidence for monoclonal expansion of epithelial cells in ovarian endometrial cysts. American Journal of Pathology $1501173-1178$.

Kao LC, Germeyer A, Tulac S, Lobo S, Yang JP, Taylor RN, Osteen K, Lessey BA \& Giudice LC 2003 Expression profiling of endometrium from women with endometriosis reveals candidate genes for disease-based implantation failure and infertility. Endocrinology 144 $2870-2881$.

Kitawaki J, Obayashi H, Ishihara H, Koshiba H, Kusuki I, Kado N, Tsukamoto K, Hasegawa G, Nakamura N \& Honjo H 2001 Oestrogen receptor-alpha gene polymorphism is associated with endometriosis, adenomyosis and leiomyomata. Human Reproduction $1651-55$.

Kitawaki J, Obayashi H, Ohta M, Kado N, Ishihara H, Koshiba H, Kusuki I, Tsukamoto K, Hasegawa G, Nakamura N, Yoshikawa T \& Honjo H 2002 Genetic contribution of the interleukin-10 promoter polymorphism in endometriosis susceptibility. American Journal of Reproductive Immunology 47 12-18.

Kosugi Y, Elias S, Malinak LR, Nagata J, Isaka K, Takayama M, Simpson JL \& Bischoff FZ 1999 Increased heterogeneity of chromosome 17 aneuploidy in endometriosis. American Journal of Obstetrics and Gynecology 180 792-797.

Kronqvist P, Kuopio T, Jalava P \& Collan Y 2002 Morphometrical malignancy grading is a valuable prognostic factor in invasive ductal breast cancer. British Journal of Cancer 87 1275-1280.

Kurose K, Gilley K, Matsumoto S, Watson PH, Zhou XP \& Eng C 2002 Frequent somatic mutations in PTEN and TP53 are mutually exclusive in the stroma of breast carcinomas. Nature Genetics 32 $355-357$.

LaGrenade A \& Silverberg SG 1988 Ovarian tumors associated with atypical endometriosis. Human Pathology 19 1080-1084.

Lalloo F \& Evans G 2001 Molecular genetics and endometrial cancer. Best Practice and Research in Clinical Obstetrics and Gynaecology $15355-363$.

Landi S, Moreno V, Gioia-Patricola L, Guino E, Navarro M, de Oca J, Capella G \& Canzian F 2003 Association of common polymorphisms in inflammatory genes interleukin (IL)6, IL8, tumor necrosis factor alpha, NFKB1, and peroxisome proliferator-activated receptor gamma with colorectal cancer. Cancer Research 63 3560-3566.

Lapp T 2000 ACOG issues recommendations for the management of endometriosis. American College of Obstetricians and Gynecologists. American Family Physician 62 1431, 1434.

Lebovic DI, Mueller MD \& Taylor RN 2001 Immunobiology of endometriosis. Fertility and Sterility 75 1-10.

Lengauer C, Kinzler KW \& Vogelstein B 1998 Genetic instabilities in human cancers. Nature 396 643-649.

Liu ET 2003 Classification of cancers by expression profiling. Current Opinion in Genetics and Development 13 97-103.

Marnellos G 2003 High-throughput SNP analysis for genetic association studies. Current Opinion in Drug Discovery and Development 6 317-321.

Martini M, Ciccarone M, Garganese G, Maggiore C, Evangelista A, Rahimi S, Zannoni G, Vittori G \& Larocca LM 2002 Possible involvement of hMLH1, p16(INK4a) and PTEN in the malignant transformation of endometriosis. International Journal of Cancer 102 398-406.

Matsuzaki S, Canis M, Murakami T, Dechelotte P, Bruhat MA \& Okamura K 2001a Expression of the cyclin-dependent kinase inhibitor p27Kip1 in eutopic endometrium and peritoneal endometriosis. Fertility and Sterility 75 956-960.

Matsuzaki S, Murakami T, Uehara S, Canis M, Sasano H \& Okamura K $2001 b$ Expression of estrogen receptor alpha and beta in peritoneal and ovarian endometriosis. Fertility and Sterility $\mathbf{7 5}$ 1198-1205.

Mayr D, Amann G, Siefert C, Diebold J \& Anderegg B 2003 Does endometriosis really have premalignant potential? A clonal analysis of laser-microdissected tissue. FASEB Journal 17 693-695.

Meresman GF, Vighi S, Buquet RA, Contreras-Ortiz O, Tesone M \& Rumi LS 2000 Apoptosis and expression of Bcl-2 and Bax in eutopic endometrium from women with endometriosis. Fertility and Sterility 74 760-766.

Mills GB, Lu Y, Fang X, Wang H, Eder A, Mao M, Swaby R, Cheng KW, Stokoe D, Siminovitch K, Jaffe R \& Gray J 2001 The role of 
genetic abnormalities of PTEN and the phosphatidylinositol 3kinase pathway in breast and ovarian tumorigenesis, prognosis, and therapy. Seminars in Oncology 28 125-141.

Mizumoto H, Saito T, Ashihara K, Nishimura M, Takehara M, Tanaka R, Ito E \& Kudo R 2002 Expression of matrix metalloproteinases in ovarian endometriomas: immunohistochemical study and enzyme immunoassay. Life Sciences 71 259-273.

Modesitt SC, Tortolero-Luna G, Robinson JB, Gershenson DM \& Wolf JK 2002 Ovarian and extraovarian endometriosis-associated cancer. Obstetrics and Gynecology 100 788-795.

Moreno-Bueno G, Gamallo C, Perez-Gallego L, de Mora JC, Suarez A \& Palacios J 2001 beta-Catenin expression pattern, beta-catenin gene mutations, and microsatellite instability in endometrioid ovarian carcinomas and synchronous endometrial carcinomas. Diagnostic Molecular Pathology 10 116-122.

Morin PJ 1999 beta-Catenin signaling and cancer. Bioessays 21 1021-1030.

Mutter GL, Baak JP, Fitzgerald JT, Gray R, Neuberg D, Kust GA, Gentleman R, Gullans SR, Wei LJ \& Wilcox M 2001 Global expression changes of constitutive and hormonally regulated genes during endometrial neoplastic transformation. Gynecologic Oncology 83 177-185.

Nakago S, Hadfield RM, Zondervan KT, Mardon H, Manek S, Weeks DE, Barlow D \& Kennedy S 2001 Association between endometriosis and $\mathrm{N}$-acetyl transferase 2 polymorphisms in a UK population. Molecular Human Reproduction 7 1079-1083.

National Statistics 2003 Cancer trends in England and Wales 19501999. (UK Government) http://www.statistics.gov.uk

Nishida M, Watanabe K, Sato N \& Ichikawa Y 2000 Malignant transformation of ovarian endometriosis. Gynecologic and Obstetric Investigation $\mathbf{5 0}$ (Suppl 1) 18-25.

Obata K \& Hoshiai H 2000 Common genetic changes between endometriosis and ovarian cancer. Gynecologic and Obstetric Investigation $\mathbf{5 0}$ (Suppl 1) 39-43.

Obata K, Morland SJ, Watson RH, Hitchcock A, Chenevix-Trench G, Thomas EJ \& Campbell IG 1998 Frequent PTEN/MMAC mutations in endometrioid but not serous or mucinous epithelial ovarian tumors. Cancer Research 58 2095-2097.

Ogawa S, Kaku T, Amada S, Kobayashi H, Hirakawa T, Ariyoshi K, Kamura T \& Nakano H 2000 Ovarian endometriosis associated with ovarian carcinoma: a clinicopathological and immunohistochemical study. Gynecologic Oncology 77 298-304.

Ohtake F, Takeyama K, Matsumoto T, Kitagawa H, Yamamoto $Y$, Nohara K, Tohyama C, Krust A, Mimura J, Chambon P, Yanagisawa J, Fujii-Kuriyama Y \& Kato S 2003 Modulation of oestrogen receptor signalling by association with the activated dioxin receptor. Nature $\mathbf{4 2 3} 545-550$.

Oral E, Ilvan S, Tustas E, Korbeyli B, Bese T, Demirkiran F, Arvas M \& Kosebay D 2003 Prevalence of endometriosis in malignant epithelial ovary tumours. European Journal of Obstetrics and Gynecology and Reproductive Biology 109 97-101.

Palacios J \& Gamallo C 1998 Mutations in the beta-catenin gene (CTNNB1) in endometrioid ovarian carcinomas. Cancer Research 58 1344-1347.

Pecorelli S, Odicino F, Maisonneuve P, Creasman W, Shepherd J, Sideri M \& Benedet J 1998 Carcinoma of the ovary. Annual report on the results of treatment in gynaecological cancer. Journal of Epidemiology and Biostatistics 3 75-102.

Prefumo F, Venturini PL \& Fulcheri E 2003 Analysis of p53 and c-erbB-2 expression in ovarian endometrioid carcinomas arising in endometriosis. International Journal of Gynecological Pathology 22 83-88.

Regidor PA, Wagner I, Ruwe M, Regidor M \& Schindler AE 2002 Morphometric analyses of endometriotic tissues to determine their grade of activity. Gynecological Endocrinology 16 235-243.

Ria R, Loverro G, Vacca A, Ribatti D, Cormio G, Roccaro AM \& Selvaggi L 2002 Angiogenesis extent and expression of matrix metalloproteinase-2 and -9 agree with progression of ovarian endometriomas. European Journal of Clinical Investigation 32 199-206.

Risinger JI, Maxwell GL, Chandramouli GV, Jazaeri A, Aprelikova $O$ Patterson T, Berchuck A \& Barrett JC 2003 Microarray analysis reveals distinct gene expression profiles among different histologic types of endometrial cancer. Cancer Research 63 6-11.

Roberts CP \& Rock JA 2003 The current staging system for endometriosis: does it help? Obstetrics and Gynecology Clinics of North America 30 115-132.

Saito M, Okamoto A, Kohno T, Takakura S, Shinozaki H, Isonishi S, Yasuhara T, Yoshimura T, Ohtake Y, Ochiai K, Yokota J \& Tanaka T 2000 Allelic imbalance and mutations of the PTEN gene in ovarian cancer. International Journal of Cancer 85 160-165.

Sampson JA 1925 Endometrial carcinoma of the ovary arising in endometrial tissue in that organ. Archives of Surgery 10 1-72.

Sato N, Tsunoda H, Nishida M, Morishita Y, Takimoto Y, Kubo T \& Noguchi M 2000 Loss of heterozygosity on 10q23.3 and mutation of the tumor suppressor gene PTEN in benign endometrial cyst of the ovary: possible sequence progression from benign endometrial cyst to endometrioid carcinoma and clear cell carcinoma of the ovary. Cancer Research $607052-7056$.

Scotti S, Regidor PA, Schindler AE \& Winterhager E 2000 Reduced proliferation and cell adhesion in endometriosis. Molecular Human Reproduction 6 610-617.

Seidman JD 1996 Prognostic importance of hyperplasia and atypia in endometriosis. International Journal of Gynecological Pathology $151-9$.

Sharpe-Timms KL 2001 Endometrial anomalies in women with endometriosis. Annals of the New York Academy of Sciences 943 $131-147$.

Starzinski-Powitz A, Handrow-Metzmacher H \& Kotzian S 1999 The putative role of cell adhesion molecules in endometriosis: can we learn from tumour metastasis? Molecular Medicine Today $\mathbf{5}$ 304-309.

Stern RC, Dash R, Bentley RC, Snyder MJ, Haney AF \& Robboy SJ 2001 Malignancy in endometriosis: frequency and comparison of ovarian and extraovarian types. International Journal of Gynecological Pathology 20 133-139.

Tamura M, Fukaya T, Murakami T, Uehara S \& Yajima A 1998 Analysis of clonality in human endometriotic cysts based on evaluation of $X$ chromosome inactivation in archival formalin-fixed, paraffinembedded tissue. Laboratory Investigation 78 213-218.

Tay ST, Leong SH, Yu K, Aggarwal A, Tan SY, Lee CH, Wong K, Visvanathan J, Lim D, Wong WK, Soo KC, Kon OL \& Tan P 2003 A combined comparative genomic hybridization and expression microarray analysis of gastric cancer reveals novel molecular subtypes. Cancer Research 63 3309-3316.

Thomas EJ \& Campbell IG 2000 Molecular genetic defects in endometriosis. Gynecologic and Obstetric Investigation 50 (Suppl 1) $44-50$.

Ueda M, Yamashita Y, Takehara M, Terai Y, Kumagai K, Ueki K, Kanda K, Yamaguchi H, Akise D, Hung YC \& Ueki M 2002a Survivin gene expression in endometriosis. Journal of Clinical Endocrinology and Metabolism 87 3452-3459.

Ueda M, Yamashita $Y$, Takehara M, Terai Y, Kumagai K, Ueki K, Kanda K, Hung YC \& Ueki M $2002 b$ Gene expression of adhesion molecules and matrix metalloproteinases in endometriosis. Gynecological Endocrinology 16 391-402.

van de Vijver MJ, He YD, van't Veer LJ, Dai H, Hart AA, Voskuil DW, Schreiber GJ, Peterse JL, Roberts C, Marton MJ, Parrish M, Atsma D, Witteveen A, Glas A, Delahaye L, van d Velde T, Bartelink H, Rodenhuis S, Rutgers ET, Friend SH \& Bernards R 2002 A gene-expression signature as a predictor of survival in breast cancer. New England Journal of Medicine 347 1999-2009.

Veltman JA, Fridlyand J, Pejavar S, Olshen AB, Korkola JE, DeVries S, Carroll P, Kuo WL, Pinkel D, Albertson D, Cordon-Cardo C, Jain AN \& Waldman FM 2003 Array-based comparative genomic hybridization for genome-wide screening of DNA copy number in bladder tumors. Cancer Research 63 2872-2880. 
Vercellini P, Scarfone G, Bolis G, Stellato G, Carinelli S \& Crosignani PG 2000 Site of origin of epithelial ovarian cancer: the endometriosis connection. BJOG: an International Journal of Obstetrics and Gynaecology 107 1155-1157.

Vidal JD, Register TC, Gupta M \& Cline JM 2002 Estrogen replacement therapy induces telomerase RNA expression in the macaque endometrium. Fertility and Sterility 77 601-608.

Vigano P, Infantino M, Lattuada D, Lauletta R, Ponti E, Somigliana E, Vignali M \& DiBlasio AM 2003 Intercellular adhesion molecule-1 (ICAM-1) gene polymorphisms in endometriosis. Molecular Human Reproduction 9 47-52.

Wang Z, Kyo S, Maida Y, Takakura M, Tanaka M, Yatabe N, Kanaya T, Nakamura M, Koike K, Hisamoto K, Ohmichi M \& Inoue M 2002 Tamoxifen regulates human telomerase reverse transcriptase (hTERT) gene expression differently in breast and endometrial cancer cells. Oncogene 21 3517-3524.

Wieser F, Schneeberger C, Tong D, Tempfer C, Huber JC \& Wenzl R 2002 PROGINS receptor gene polymorphism is associated with endometriosis. Fertility and Sterility 77 309-312.

Wieser F, Fabjani G, Tempfer C, Schneeberger C, Sator M, Huber J \& Wenzl R 2003 Analysis of an interleukin-6 gene promoter polymorphism in women with endometriosis by pyrosequencing. Journal of the Society for Gynecologic Investigation 10 32-36.

Witz CA, Takahashi A, Montoya-Rodriguez IA, Cho S \& Schenken RS 2000 Expression of the alpha2beta1 and alpha3beta1 integrins at the surface of mesothelial cells: a potential attachment site of endometrial cells. Fertility and Sterility 74 579-584.

Wu Y, Basir Z, Kajdacsy-Balla A, Strawn E, Macias V, Montgomery K \& Guo SW 2003 Resolution of clonal origins for endometriotic lesions using laser capture microdissection and the human androgen receptor (HUMARA) assay. Fertility and Sterility $\mathbf{7 9}$ (Suppl 1) 710-717.

Yoshikawa H, Jimbo H, Okada S, Matsumoto K, Onda T, Yasugi T \& Taketani Y 2000 Prevalence of endometriosis in ovarian cancer. Gynecologic and Obstetric Investigation 50 (Suppl 1) 11-17.

Zaino R, Whitney C, Brady MF, DeGeest K, Burger RA \& Buller RE 2001 Simultaneously detected endometrial and ovarian carcinomas - a prospective clinicopathologic study of 74 cases: a gynecologic oncology group study. Gynecologic Oncology 83 $355-362$

Zondervan KT, Cardon LR \& Kennedy SH 2001 The genetic basis of endometriosis. Current Opinion in Obstetrics and Gynecology 13 $309-314$

Received 26 September 2003

First decision 13 November 2003

Accepted 18 December 2003 